\title{
Gastrocolic Fistula Presented as an Early Complication of Gastric Surgery in a 42-year-old Man
}

\author{
Mohammad Javad Zahedi ${ }^{1,2,3}$, Sara Shafiei pour ${ }^{1.4 *}$, Masood Dehghani ${ }^{5}$, Nazanin Eslami ${ }^{4}$
}

1. Gastroenterology and Hepatology Research Center, Kerman University of Medical Sciences, Kerman, Iran

2. Physiology Research Center, Gastroenterology and Hepatology Research Center, Kerman University of Medical Sciences, Kerman, Iran

3. Institute of Basic and Clinical Physiology Sciences, Kerman University of Medical Sciences, Kerman, Iran

4. Clinical Research Unit, Afzalipour Hospital, Kerman University of Medical Sciences, Kerman, Iran

5. Department of surgery Afzalipour University Hospital, Kerman University of Medical Sciences, Kerman, Iran

\footnotetext{
* Corresponding Author:

Sara Shafieipour, MD

Department of Gastroenterology, Afzalipour Hospital, Kerman University of Medical Sciences, Kerman, Iran Telefax: +98 3413257470 Email: sarashafieipour@yahoo.com.
}

Received: 18 Nov. 2016 Accepted: 02 Feb. 2017

\section{ABSTRACT}

Currently, surgery is less needed for the treatment of refractory peptic ulcer disease (PUD) or its complications. So, the complications of PUD surgery have been clearly declined. Here in, we present a 42-year-old man with chronic watery diarrhea and significant weight loss during 2 years after gastrojejunostomy for the treatment of obstructive PUD. Small bowel gastrointestinal series showed rapid transit without passage of contrast in the parts of small bowel. The patient was scheduled for exploratory laparotomy. During the surgery a large fistula was detected between the stomach and transverse colon, which was repaired. At the follow-up 6 months after the surgery, the patient did not have any history of recurrence of diarrhea and had $10 \mathrm{~kg}$ weight gain. Gastrocolic fistula is a very rare complication of surgical management of PUD. Barium enema is the most helpful imaging procedure for the diagnosis of gastrocolic fistula and surgery after correction of nutritional status is suggested especially for malnourished patients.

\section{KEYWORDS:}

Gastrocolic fistula; Gastric surgery; Peptic ulcer ; Complications

Please cite this paper as:

Zahedi MJ, Shafiei pour S, Dehghani M, Eslami N. Gastrocolic Fistula Presented as an Early Complication of Gastric Surgery in a 42-year-old Man. Middle East J Dig Dis 2017;9:114-117. DOI:10.15171/mejdd.2017.61.

\section{INTRODUCTION}

Currently, with appropriate medical treatment of peptic ulcer disease (PUD) with proton pump inhibitors and helicobacter pylori infection eradication, gastric surgery is infrequently needed for the management of resistant PUD and its complications. So, the complications of surgery for the treatment of PUD have been dramatically decreased. ${ }^{1}$

Common complications of PUD such as dumping syndrome, post vagotomy diarrhea, and afferent and efferent loop syndrome, which are generally nominated as postgastrectomy syndromes are often self limited and in less than $1 \%$ of cases become progressive and debilitating. ${ }^{2}$ Furthermore, postgastrectomy syndromes are more seen in special surgical techniques such as vagotomy to resection. ${ }^{2,3}$

Here in, we present a very rare complication of gastric surgery in a patient with medical history of PUD that was manifested by debilitating chronic diarrhea.

\section{CASE REPORT}

A 42-year-old man was admitted to our hospital for assessment of chronic watery diarrhea. His complaint had been started about 8 months 
Table 1: Serial laboratory tests of the patient

\begin{tabular}{|c|c|c|c|}
\hline Parameter & Normal range & 5 months before admission & On admission \\
\hline WBC $\left(\right.$ per $\left.\mathrm{mm}^{3}\right)$ & $4500-11,000$ & 5000 & 5500 \\
\hline $\mathrm{Hgb}(\mathrm{g} / \mathrm{dL})$ & $13.5-17.5$ (men) & 13 & 11 \\
\hline Platelet count (per mm³) & $150-4500000$ & 290000 & 480000 \\
\hline Fasting blood glucose (mg/dL) & $70-110$ & 98 & 90 \\
\hline Creatinine (mg/dL) & $0.8-1.2$ & 0.9 & 1 \\
\hline Albumin (g/dL) & $3.3-5.0$ & 4 & 2.8 \\
\hline Total protein $(\mathrm{g} / \mathrm{dL})$ & $6.0-8.3$ & 6.7 & 5.5 \\
\hline Sodium $(\mathrm{mmol} / \mathrm{L})$ & $135-145$ & 140 & 137 \\
\hline Potassium (mmol/L) & $3.4-4.8$ & 3.8 & 1.8 \\
\hline \multicolumn{4}{|l|}{ Immunoglobulins (mg/dL) } \\
\hline $\operatorname{IgA}$ & $80-300$ & 98 & \\
\hline $\operatorname{IgG}$ & $650-1295$ & 800 & \\
\hline $\operatorname{IgM}$ & $70-334$ & 234 & \\
\hline Prothrombin time $(\mathrm{sec})$ & $11.0-13.7$ & 13 & 15 \\
\hline International normalized ratio for Prothrombin time & 1 & 1 & 1.8 \\
\hline Ferritin $(\mu \mathrm{g} / \mathrm{dL})$ & $30-250$ & 69 & 10 \\
\hline $\operatorname{ESR}(\mathrm{mm} / \mathrm{hrs})$ & $0-15$ (men) & 5 & 5 \\
\hline TSH $(\mathrm{mIU} / \mathrm{mL})$ & $0.5-4$ & 2 & \\
\hline Serum gastrin $(\mathrm{pg} / \mathrm{mL})$ & below 100 & 35 & \\
\hline Anti-tissue transglutaminase antibodies $(\operatorname{Ig} \mathrm{A}) \mathrm{IU} / \mathrm{mL}$ & below 10 & Neg & \\
\hline Anti H. pylori Ig Ab IU/mL & below 40 & 10 & \\
\hline
\end{tabular}

earlier and progressed by time. The frequency was 8 to 10 times per day without pain or bloody diarrhea, which was aggravated by eating but was constant during fasting and could awake him during sleeping. He had $20 \mathrm{Kg}$ weight loss during this time and recently he complained of progressive fatigue and walking disability. ${ }^{5}$ months ago, he also had been assessed for this problem and underwent diagnostic laboratory tests (table1). Upper and lower gastrointestinal (GI) endoscopy with biopsy at that time was normal. To rule out Zollinger Ellison syndrome, fasting gastrin serum was performed, which was $35 \mathrm{pg} / \mathrm{mL}$ and octeroscan was normal. Empirical therapy with metronidazole and ciprofloxacin was started with the impression of blind loop syndrome but his condition did not improve.

In his medical history, he had abdominal pain, postprandial vomiting, and weight loss about 2 years ago. He had undergone gastrojejunostomy for the treatment of bowel obstruction due to duodenal ulcer. He did not have a history of travel, recurrent infections, and high risk sexual contact. He was married and did not have a history of any significant diseases in his family.

In physical examination, he was pale and cachectic. His vital signs were normal. No lymphadenopathy, thyromegaly, heart murmur, and abnormal sound in lung were detected. The abdomen was soft with midline surgical scar without tenderness and organomegaly. In neurological examinations he had proximal weakness in his four limbs. Mild pitting edema was detected in lower extremities. Other exams were normal.

The results of laboratory tests on admission are shown in the table. Significant findings were sever hypokalemia $(\mathrm{K}=1.8 \mathrm{mmoL} / \mathrm{L})$, mild anemia $(\mathrm{Hgb}=11 \mathrm{~g} / \mathrm{dL})$ and low serum albumin level $(\mathrm{Alb}=2.8 \mathrm{~g} / \mathrm{dL})$. Stool exam was normal. Sudan $\amalg$ staining and stool collection for the measurement of fat were not be performed. 


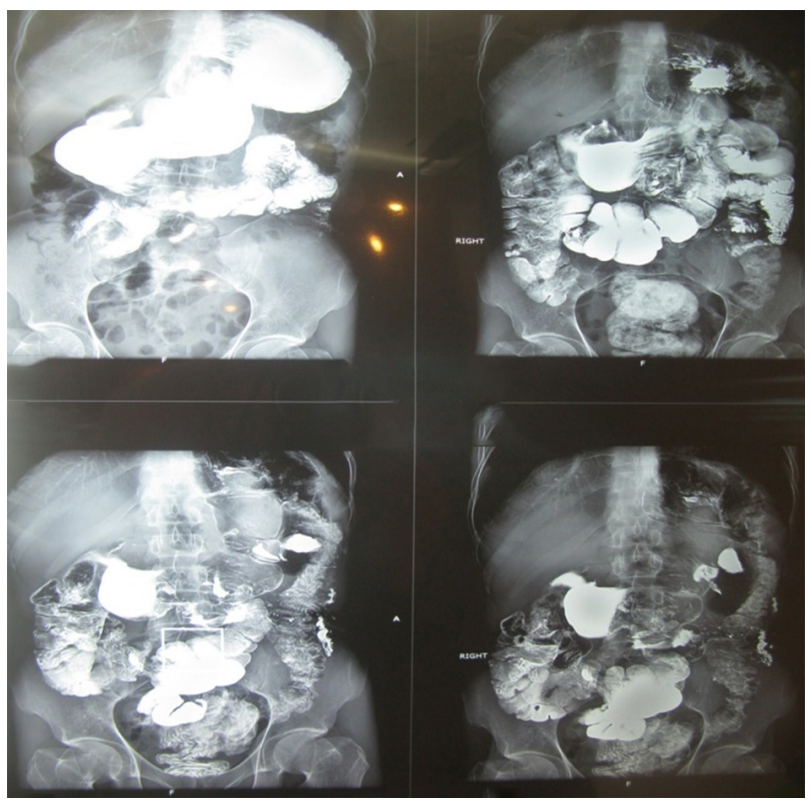

Fig.1: Rapid transit time in small bowel to transverse colon and bypass of the most parts of the small intestine is shown.

Abdominal computed tomography (CT) with contrast was normal. Transit of small bowel showed rapid transit time in small bowel and bypass of some parts of it (figure 1).

According to the result of upper GI series, after correction of potassium abnormality and improving the nutritional status with total parenteral nutrition (TPN), we scheduled him for exploratory laparotomy. During the surgery, a 5-cm fistula was detected between the inferior wall of the body of stomach and transverse colon. The repair of gastrocolic fistula was performed in one-stage surgery.

He was discharged from the hospital 7 days after surgery without any complaint of diarrhea. During 6 months follow-up, he was in remission and had about $10 \mathrm{~kg}$ weight gain.

\section{DISCUSSION}

Chronic diarrhea, which is defined as diarrhea lasts longer than 4 weeks, is not uncommon after gastric surgery. Dumping syndrome, intestinal hurry, small bowel bacterial overgrowth, pancreatic insufficiency, and bile acid malabsorption are major causes of it. ${ }^{3,4}$ Gastrocolic fistula is a very rare and late complication of gastric surgery, which is manifested by chronic diarrhea. Our knowledge about gastrocolic fistula after gastric surgery is limited to case reports and small published case series. ${ }^{5,6}$

GI fistula mostly occurs 20-30 years after gastric surgery. ${ }^{5}$ Malnutrition, use of glucocorticoids, emergency surgery, and surgical technical defects such as inadequate gastric resection, and incomplete vagotomy can predispose to it. ${ }^{7,8}$

Diarrhea, weight loss, and fecal vomiting or fecal odor are most common manifestations of gastrocolic fistula, which was seen in $80 \%, 82 \%$, and $32 \%$ of patients, respectively. Diarrhea is mostly sever and debilitating. It is often watery and contains food particles and may be bloody in $15 \%$ of cases. It may become worse with eating and supine position. ${ }^{9}$

When gastrocolic fistula is suspected, upper GI series and barium enema should be performed. Barium enema is the most helpful diagnostic procedure with 95\% sensitivity. Upper and lower GI endoscopy and CT enterography may show the fistula but they are usually performed to rule out other causes of chronic diarrhea. ${ }^{7,10,11}$

Early management of GI fistula is correction of electrolyte abnormalities and enhancement of nutritional condition with TPN. Malnourished patients with GI fistula in distal small bowel and colon were candidate to surgery. ${ }^{7,10,12}$

In conclusion, Gastrocolic fistula is a very rare complication of gastric surgery but should be considered in all patients with complaint of chronic diarrhea after gastric surgery. Barium enema is the most helpful diagnostic imaging test. Surgery should be recommended especially for malnourished patients.

\section{CONFLICT OF INTEREST}

The authors declare no conflict of interest related to this work.

\section{REFERENCES}

1. Kauffman GL Jr. Duodenal ulcer disease: treatment by surgery, antibiotics, or both. Adv Surg 2000;34:121

2. Glasgow RE, Mulvihill SJ. Postgastrectomy syndromes. Probl General Surgery 1997;14:132.

3. Eagon JC, Miedema BW, Kelly KA. Postgastrectomy syndromes. Surg Clin North Am 1992;72:445 65. doi: 10.1016/S0039-6109(16)45689-6 
4. Miedema BW, Kelly KA. The Roux operation for postgastrectomy syndromes. Am J Surg 1991;161:25661. doi: 10.1016/0002-9610(91)91141-5

5. Damata G, Rahili A, Karimdjee-Soilihi B, Gelsi E, Avallone S, Benchimol D. Gastrojejunocolic fistula after gastric surgery for duodenal ulcer: case report. G Chir 2006;27:360-2.

6. Subramaniasivam N, Ananthakrishnan N, Kate V, Smile SR, Jagdish S, Srinivasan K: Gastrojejunocolic fistula following surgery for peptic ulcer. Trop Gastroenterol 1997;18:183-7.

7. Kece C, Dalgic T, Nadir I, Baydar B, Nessar G, Ozdil B, Bostanci EB. Current Diagnosis and Management of Gastrojejunocolic Fistula. Case Rep Gastroenterol 2010;4:173-77. doi:10.1159/000314048

8. Wang XB, Ren JA, Li JS. Sequential changes of body composition in patients with enterocutaneous fistula during the 10 days after admission. World $J$ Gastroenterol 2002;8:1149-152. doi: 10.3748/WJG. v8.i6.1149

9. MARSHALL SF, KNUD-HANSEN J. Gastrojejunocolic and gastrocolic fistulas. Ann Surg 1957; 145:770-8210.

10. Kim KH, Jee YS. Gastrojejuno-colic fistula after gastrojejunostomy. J Korean Surg Soc 2013;84:252-5. doi : $10.4174 / \mathrm{jkss} .2013 .84 .4 .252$

11. Pickhardt PJ, Bhalla S, Balfe DM. Acquired gastrointestinal fistulas: classification, etiologies, and imaging evaluation. Radiology 2002;224:9-23. doi:10.1148/ radiol.2241011185

12. Levy E, Frileux P, Cugnenc PH, Honiger J, Ollivier JM, Parc R. High-output external fistulae of the small bowel: Management with continuous enteral nutrition. $\mathrm{Br}$ J Surg 1989;76:676-9. doi: 10.1002/bjs.1800760708. 